\section{SPOTLIGHT ON DENTAL SHOWCASE}

- Carestream Dental showed off the newly refined CS R4 Clinical+ practice management software. The new software offers exceptional features to help you analyse your practice performance with ease and achieve your KIPs. Optional extras such as the eSignatures module, AutoPost and Online Appointmentor Booking System help to further streamline your workflow while enhancing the patient experience. www.carestreamdental.co.uk

- Christie + Co were delighted to host so many interested visitors on their stand and said the confidence in the market demonstrated at the show is very positive. Christie + Co are specialist property advisers and can work closely with you if you are thinking of buying or selling a dental business. Call 02072270749.

- The team at Healthcare Learning: Smile-on extolled the benefits of the MSc in Restorative \& Aesthetic Dentistry, offered with the University of Manchester, as well as the MSc in Endodontics. The team has also launched a brand new initiative: 'Healthy Working: an ergonomic approach to dentistry for a pain-less career'. www.healthcare-learning.com

- Voco presented several proven and innovative products such as Futurabond $\mathrm{M}+$, a universal one-component adhesive in bottles. Another highlight was IonoStar Molar, a new glass ionomer restorative material in an innovative application capsule. The material is applied without conditioner or adhesive and scores particularly highly thanks to its non-sticky consistency and perfect marginal adaptation. www.voco.com

- 3M ESPE demonstrated an exciting breakthrough in restorative dentistry, the brand new Filtek Bulk Fill posterior restorative. With excellent handling and polish retention and low wear for durability, it requires no capping layer, enabling clinicians to reduce procedure times and costs. 3M ESPE is a trademark of the 3M company. www.3Mespe.co.uk

- Eschmann Direct launched a major initiative at this year's BDIA Showcase for practitioners looking to invest in a new autoclave with unbeatable value. The full comprehensive package offers free installation and commissioning, CPD training, free 12 month log book tailored to your Eschmann equipment, comprehensive guarantee and a market leading Lifetime Breakdown. www.eschmann.co.uk

- WhiteWash Laboratories showed Showcase visitors their new WhiteWash Dissolving Whitening Strips that vanish after 20 minutes, yet give great results. Their new, ultrathin and flexible trays were on show too, and new WhiteWash economical pink and black electric toothbrushes that help raise awareness of breast and prostate cancer. www.whitewashlaboratories.com

\title{
THE LATEST IN TREATMENT CENTRES
}

Henry Schein Dental's new INTEGO treatment centre from Sirona is beautifully built and available in a range of vibrant colours to suit all surgeries.

INTEGO's features focus on ergonomic operating procedures and patient comfort. It has an intuitive EasyPad interface and features a flexible compact water unit. The INTEGO is very affordable and is a flexible, stylish addition to any surgery.

The first 25 Integos purchased will receive six FREE Sirona Turbines or Contra-angles - call 08700102041 to find out more. www.henryschein.co.uk

\section{CLOTHS IMPREGNATED WITH NANOSILVER}

Unlike conventional cloths, Evident's range of reusable, washable microfibre cloths, e-cloth Professional, have 30,000 fibres per square inch and more than 500 million fibre strands per cloth. These special fibres are capable of entangling and thus remove a wide range of pathogenic particles. When damp, their capillary action rapidly draws contamination into the fibre gaps, making them effective in removing grease, dirt and bacteria from surfaces, which other cloths leave behind. In addition, every individual cloth is impregnated with antimicrobial nanosilver, which remains active throughout the life of the cloth.

Successfully removing over 99\% of bacteria from surfaces without the need for harsh, needlessly expensive cleaning products, e-cloth Professional is extremely cost-effective and eco-friendly, helping save time and money just by using water. Plus these cloths are washable (guaranteed up to 1,000 washes) so can be reused again and again. Following National Patient Safety Agency guidelines e-cloth Professional cloths are available in packs of ten in yellow, blue, red or green.

Call 0500321111 or visit www.evident.co.uk.

\section{FOR RAPID CLEANING AND DISINFECTION}

Scientifically developed for rapid cleaning and disinfection, Alkapharm wipes have traditionally been an advantageous choice for any practice's infection control routine.

Now, for the same great value as ever, you can get 250 wipes that are now 20\% bigger. The high quality wipes are formulated to both clean and disinfect in one easy application and the increased size means even better value.

Available dispense tub and refill packs, the wipes are formulated for the cleaning and high level disinfecting non-invasive medical devices and small pieces of medical and dental equipment within all areas that can pose a risk to both patient and staff from cross contamination.

For high quality infection control and great value products choose Alkapharm. To find out more and to explore the full range available, ask your dealer representative or visit the website today.

For more information call 01785714919 or visit www. alkapharm.co.uk.

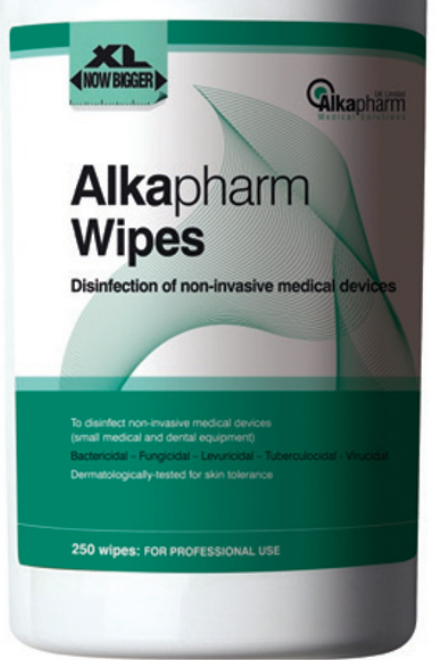

545 